\title{
Vanguardia, vigencia y viabilidad de la accountability societal concebida por Guillermo 0'Donnell*
}

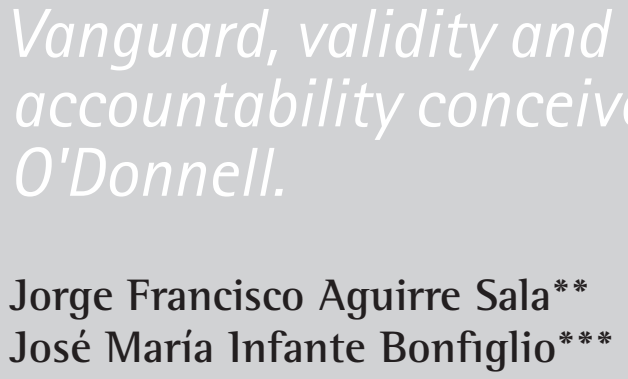

\section{RESUMEN}

A partir de la obra colectiva Controlando la política. Ciudadanos y medios en las nuevas democracias latinoamericanas (2002), donde Guillermo O'Donnell debate el concepto de rendición de cuentas con Peruzzotti, Smulovitz y Przeworski, se rescata la agenda de investigación propuesta por O'Donnell. La indagatoria pretende explicitar la tipología de la accountability con sus respectivos criterios; caracterizar la accountability societal; mostrar la necesidad, vanguardia y vigencia de la propuesta de O'Donnell; y, dados sus condicionamientos explícitos a la "combinación de tiempo, información, acceso a media, capacidad de comunicación pública e interpersonal", evaluar su posible implementación con los aportes de la actual era digital. La metodología para los tres primeros objetivos sigue el análisis conceptual desarrollado por O'Donnell y otros estudios sobre su pensamiento al respecto. Para el último objetivo, se hace una prospectiva donde los instrumentos cibernéticos puedan funcionar a favor de la accountability societal.

PALABRAS CLAVE

Rendición de cuentas, capital simbólico, mass media tradicionales, redes sociales.

\begin{abstract}
From the collective work Controlling politics. Citizens and the media in the new Latin American democracies (2002), where Guillermo O'Donnell debates the concept of accountability with Peruzzotti, Smulovitz and Przeworski, rescues the research agenda proposed by O'Donnell. The examination aims to make explicit the typology of accountability with its respective criteria; characterize evaluate their possible implementation with the contributions of the current digital age. The methodology for the first three objectives follows the conceptual analysis developed by O'Donnell and other studies on his thoughts. For the last objective, a prospective is made where cybernetic instruments can work in favor of societal accountability.
\end{abstract}

\section{KEYWORDS}

Accountability, symbolic capital, traditional mass media, social networks.

\footnotetext{
*Artículo recibido el 11 de agosto de 2017 y aceptado para su publicación el 30 de noviembre de 2017.

** Universidad Autónoma de Nuevo León, Instituto de Investigaciones Sociales (jorgeaguirresala@ @otmail.com; jorge.aguirres@uanl.mx) ORCID: 0000-0002-5805-4082

*** Instituto de Investigaciones Sociales, Universidad Autónoma de Nuevo León (jose.infanteb@uanl.mx) oRCiD: 0000-0003-2678-546X
} 


\section{SUMARIO}

1. Introducción

2. Las diversas clases de rendición de cuentas

3. Características de la accountability societal

4. Vanguardia y vigencia de la propuesta de Guillermo O'Donnell

5. La accountability societal a prueba en los new media

6. Conclusiones

\section{INTRODUCCIÓN}

La lucidez de Guillermo 0'Donnell, al indagar y describir los modos de controlar el poder en el gobierno, le llevó a debatir y precisar las modalidades de la accountability (rendición de cuentas) para defender la soberanía de los ciudadanos. O’Donnell trabajó constantemente para vitalizar las diversas modalidades de rendición de cuentas entre sí y complementar lo que otros teóricos no conceptualizaron. A partir de las propuestas de Smulovitz y Peruzzoti, aparecidas al inicio del siglo XXI, ${ }^{1}$ O'Donnell revisó su propuesta sobre las vías para "horizontalizar" la accountability societal y hacer efectiva la defensa de la soberanía ciudadana en términos de acotar el poder gubernamental a la legalidad y lograr la corrección de ese mismo poder cuando presenta desvíos.

Su visionaria propuesta no quedó exenta de retos; entre otros, el de abonar capital social ante las nuevas formas ciudadanas de participar en política, tales como la gobernanza, el gobierno abierto y el tipo de activismo que en la actual era digital ofrecen los nuevos medios. La historia ha puesto a prueba la construcción y horizontalización de la accountability societal vislumbrada por O'Donnell, y ésta no sólo resultó airosa, sino ejemplar.

Para dar cuenta de ello, se rescata la "agenda de investigación" propuesta por O’Donnell con los siguiente objetivos: explicitar la tipología de la rendición de cuentas con sus respectivos criterios; caracterizar la rendición de cuentas societal; mostrar la necesidad, vanguardia y vigencia de la propuesta de O’Donnell; y, por su aspecto comunicativo explícito vinculado con la “combinación de tiempo, información, acceso a media, capacidad de comunicación pública e interpersonal”, evaluarla en el contexto de la actual era digital.

La metodología para los tres primeros objetivos sigue el análisis conceptual que desarrolló 0’Donnell y otros estudios sobre su pensamiento al respecto.

\footnotetext{
'Smulovitz, Catalina y Peruzzottı, Enrioue, "Societal Accountability in Latin America", Journal of Democracy, vol. 11, núm. 4, pp. 147-158.
} 
Para el último objetivo, se hace una prospectiva donde los instrumentos cibernéticos funcionan a favor de la horizontalización de la accountability societal.

\section{LAS DIVERSAS CLASES DE RENDICIÓN DE CUENTAS}

Hablar de una tipología de la rendición de cuentas presupone una definición más o menos universalmente aceptada del concepto. Desde aquí comienzan las dificultades. Hemos resuelto aceptar la costumbre de Guillermo 0'Donnell ${ }^{2}$ de no traducir el término, lo cual no deja las cosas más claras, pero es un principio de acuerdo para lograr un mayor consenso. Accountability se deriva de accountable, un término del inglés de la Alta Edad Media que presenta dos campos semánticos: el de las expectativas de dar cuenta de las propias acciones (referido a un sujeto social) y el de la capacidad de ser explicado (un acto o acción particular); es decir, de asumir una responsabilidad o elaborar un acto social de manera tal que se expresen sus motivaciones o agentes causales.

En el primer caso, es un acto inherente al agente y en el segundo hay un contexto que exige la explicación. Se trataría, por un lado, de la conciencia de responsabilidad; por otro, de la conducta que siguen las instituciones sociales. Esto proporciona diferentes posibilidades a la acción social, ya que sin duda es más difícil actuar sobre la subjetividad que sobre las normas institucionales. Como veremos, el mismo 0'Donnell hablaba a veces de accountability como un tema de responsabilidad, lo cual se referiría a las condiciones subjetivas de los agentes; en otras ocasiones, lo atribuía a una condición del sistema político.

La posibilidad de ejercer cierto control sobre las acciones de los gobernantes estaba ya en el pensamiento político griego, pero se agudizó en el siglo xx, con la discusión sobre la calidad de la democracia y sus instituciones.

En realidad, es recién a fines del siglo xx cuando podemos encontrar un predominio de los sistemas democráticos en el gobierno de las naciones. Gianfranco Pasquino ${ }^{3}$ presenta un listado según el cual en el mundo del año 1900 había sólo nueve Estados democráticos frente a 42 no democráticos; para el año 2000 las cifras eran de 86 y 104, respectivamente. Muchos de esos Estados llamados democráticos presentaban un funcionamiento deficiente con relación a un modelo democrático, pero presentaban diferentes formas de autoritarismo. Esto proporciona sentido a la idea de accountability, ya que es propio

\footnotetext{
${ }^{2}$ O'Donnell, Guillermo, "Accountability horizontal: la institucionalización legal de la desconfianza política", POSTData, Revista de Reflexión y análisis político, núm. 7, pp. 11-34. O'DonnelL, GuIllermo, Disonancias: críticas democráticas a la democracia, Buenos Aires, Prometeo, 2007.

${ }_{3}^{3}$ Pasquino, Gianfranco, Nuevo curso de ciencia política, México, Fondo de Cultura Económica, p. 288, 2001.
} 
de todos los sistemas autoritarios evadir cualquier tipo de rendición de cuentas en relación con los ciudadanos.

Manuel Sánchez de Dios ${ }^{4}$ hace una diferencia entre responsabilidad jurídica y responsabilidad política. Señala que la articulación de ambas es un problema central y clásico en la teoría política. De hecho, algunos autores piensan que a partir de la existencia de leyes escritas puede hablarse de justicia y ejercer un control sobre las acciones de los gobernantes, ${ }^{5}$ de manera que es inevitable, al hablar de responsabilidad política, aludir a la legislación que regula las condiciones del ejercicio de la función. Manuel Sánchez de Dios retoma las cinco condiciones de la responsabilidad política desarrolladas por Zafra: ${ }^{6}$ la capacidad administrativa del gobernante; su comprensión sobre los fines del Estado y sobre el interés colectivo; su interpretación y la utilización de los poderes asignados por las leyes y reglamentos; el modo en que especifica las prioridades de los asuntos públicos de su competencia; y el de la capacidad para prever las consecuencias de sus decisiones.

Se trata, en varios de los niveles, de la capacidad de administrar en la acción gubernamental, lo cual sería un problema de competencia (y como tal puede evaluarse) pero no es una propiedad discernible de un agente: la capacidad administrativa se ha obtenido mediante estudios y entrenamiento apropiados, igualmente con su interpretación sobre los poderes atribuidos y con la capacidad especificar prioridades en asuntos públicos (lo cual se refiere a su sustento ideológico). La necesidad de prever las consecuencias de sus acciones responde a sus estructuras psicológicas, a procesos cognitivos y a la capacidad para manejar información específica; pero tenemos dudas acerca de qué es la condición moral más allá de la capacidad de emitir un juicio moral.

Es importante debatir y analizar cuáles son los conocimientos que debería tener un agente político y qué ocurriría con los aspirantes a posiciones de administración que carecieran de esos conocimientos. Recurrentemente, se presentan ideas sobre someter a candidatos y gobernantes a exámenes de competencias, pero, además de las complicaciones técnicas que tal cosa implica, atenta contra la idea democrática de igualdad y eliminación de sistemas elitistas.

\footnotetext{
${ }^{4}$ Sánchez de Dios, Manuel, "Nueva perspectiva de la responsabilidad política", Revista de las Cortes Generales, núm. 67, p. 147.

${ }^{5}$ Garcia Gual, Carlos, "La Grecia Antigua", en Fernando Vallespín (ed.), Historia de la teoría política, I, Madrid, Alianza, 1990, p. 62

${ }^{6}$ ZAFRA, JoSÉ, "Responsabilidad política del gobierno: cuestiones fundamentales", en M. Ramírez (ed.), El control parlamentario en las democracias pluralistas, Barcelona, Labor, p. 102.
} 
Para algunos autores, la accountability es un elemento esencial para evaluar la calidad de la democracia; Dirk Berg-Schlosser ${ }^{7}$ recalca que la accountability del ejecutivo es una cualidad específica de la democracia; también menciona una accountability horizontal, que descansa en los controles parlamentarios y judiciales. Su contrapartida, la accountability vertical, depende de las percepciones del público y de los medios pluralistas independientes; de resultar insatisfactorias, puede restaurarse en las siguientes elecciones; es decir que mientras que la accountability horizontal sería una debilidad o fortaleza estructural, la vertical correspondería a condiciones temporales.

Parece difícil hablar de accountability sin referencia obligatoria a la democracia, una condición previa e insoslayable. Leonardo Morlino ${ }^{8}$ proporciona una definición mínima de una "buena" democracia en oposición a otras formas de democracia a las que califica como defectivas. Este sería el caso de las democracias excluyentes, las democracias de dominio, las iliberales y las declinativas de la soberanía (que 0’Donnell llama delegativas). Cuatro características deberían existir en un sistema político como condición sine qua non para ser aceptado como democrático en sentido fuerte: sufragio universal; elecciones de juego limpio, competitivas, libres y periódicas; la existencia de al menos dos partidos políticos en relativa igualdad de condiciones; $y$, por último, más de una fuente independiente, libre y confiable de información.

Una buena democracia presenta cinco dimensiones variables: las dos primeras son dimensiones procesales y las dos últimas son sustantivas: la vigencia del Estado de derecho; la accountability; una cierta correspondencia entre el sistema político y las aspiraciones y deseos de los ciudadanos y la sociedad en general; el respeto total a los derechos y garantías; y la perseverancia en la implementación progresiva de mecanismos de igualdad política, económica y social.

Morlino define la accountability como la obligación de los dirigentes electos de responder por sus decisiones políticas cuando son cuestionados por los electores u otros organismos o instituciones constitucionales. Esto supone dos postulados: ciudadanos capaces de evaluar adecuadamente la responsabilidad de los gobiernos en términos de satisfacción de las necesidades e intereses de los ciudadanos, ya sea individualmente ya en conjunto; y que esta evaluación la hagan los propios ciudadanos, así sean tomados de modo aislado o como

\footnotetext{
${ }^{7}$ BeRg-SCHLOSSER, DICK, "The quality of democracies in Europe as measured by current indicators of democratization and good governance", Journal of Communist Studies and Transition Politics, vol. 20, núm. 1, p. 30.

${ }^{8}$ Morlino, Leonardo, "What is 'good' democracy?", Democratization, vol. 11, núm. 5, 2004, pp. 10-32.
} 
grupo, es decir que no habrá un tercero que pueda actuar o decidir sobre estas necesidades.

Para Guillermo 0'Donnell, la accountability se presenta en dos campos o dominios: horizontal y vertical. Muchos autores, como Berg-Schlosser y otros, parten de la distinción de 0’Donnell. Por accountability vertical 0’Donnell ${ }^{9}$ ubica una característica dinámica de las democracias políticas llamadas poliarquías. ${ }^{10}$ En estas, la accountability vertical es una característica del sistema electoral de las democracias en la que deben presentarse elecciones libres e institucionalizadas, mediante las cuales los ciudadanos pueden premiar o castigar a los candidatos y gobernantes, ratificándolos o votando por alguno de la oposición (o votando en blanco, si fuera necesario). Esto supone la existencia de mecanismos de reelección (condición ausente en varios sistemas electorales latinoamericanos hasta fechas recientes).

En las poliarquías debe existir también acceso a la información mediante fuentes variadas que permitan presentar demandas públicas y legales y denunciar posibles delitos. Para 0'Donnell, la espacialidad temporal de las elecciones es un inconveniente con diferentes derivaciones o incidentes. Otro inconveniente se deriva de que algunos estudios ponen en duda la capacidad de las elecciones para sancionar o evaluar la acción de los gobernantes. En los últimos tiempos, además, los medios se convirtieron en sustitutos de la opinión de los ciudadanos, dirigiendo la atención de la opinión pública hacia aspectos que en ocasiones pueden no ser los más importantes para la población. En los Estados Unidos, después de la Segunda Guerra Mundial, los estudios de opinión llegaron a ser el medio preferido por los gobernantes para tener esta evaluación. Fue muy notoria la dependencia de Ronald Reagan a los estudios de opinión para la toma de decisiones.

Recientemente se han propuesto otros mecanismos, como cierta clase de referéndums o de ratificación de mandatos para dar una posibilidad de evaluación ciudadana en los periodos que transcurren entre eventos electorales, pero se trata de medidas extraordinarias de complicada ejecución. En la definición 136 que propone José María Maravall ${ }^{11}$ para la condición de accountability, sólo se toma en cuenta esta perspectiva. Un gobierno posee esta característica cuando los ciudadanos pueden responsabilizarlo de sus acciones y, consecuentemente, castigarlo o premiarlo en los procesos electorales.

\footnotetext{
${ }^{9}$ O'Donnell, Guillermo, Disonancias: críticas democráticas a la democracia, Buenos Aires, Prometeo, 2007, p. 86.

${ }^{10}$ DahL, Robert, La poliarquía. Participación y oposición, Madrid, Tecnos, 1989.

11 Maravall, José Maria, Accountability and the survival of governments, Madrid, Centro de Estudios Avanzados en Ciencias Sociales, 2005.
} 
En cuanto a la accountability horizontal, ${ }^{12}$ 0'Donnell propone la existencia de instituciones del Estado que posean el poder legal de emprender acciones que van desde un control cotidiano hasta la imposición de sanciones o el impeachement con relación a las operaciones y omisiones de las otras instituciones del Estado. Además, están preparadas y habilitadas para hacerlo. Estas acciones corresponden a tres esferas: la de la democracia y su dinámica, la liberal y la republicana. Respecto a la democracia, se trata de aquellos actos que impiden la realización de elecciones libres, competidas y con igualdad de oportunidades. O’Donnell no las considera debido a que la aparición de estos aspectos excluiría esos casos del análisis de los modelos democráticos.

La esfera liberal es vulnerada cuando las instituciones del Estado incumplen con su función de controlar y castigar la violación a los principios de las garantías y libertades de los ciudadanos, como cuando esta violación se hace a partir de organismos menores o laterales y de ello se derivan violaciones de domicilios, violencia doméstica, juicios arbitrarios o diversas formas de tortura y supresión de las libertades de expresión y asociación. Por último, la esfera republicana es afectada cuando los funcionarios, hayan llegado mediante elecciones o cualquier otro proceso, adoptan decisiones que anulan las formas republicanas y se conducen con arreglo a modos particularistas, beneficiándose a sí mismos o a su grupo y priorizan intereses privados.

Probablemente sea más pertinente hablar de grados de accountability antes que de tipologías. Para lo cual habría que crear (y fundamentar) las escalas correspondientes. Si tomamos como referente contemporáneo al Banco Mundial para evaluar el estado de globalización que guardan las naciones, es insoslayable la inclusión que hace de la accountability como uno de los rasgos de buena gobernabilidad. ${ }^{13}$ En efecto, el concepto ha cambiado desde fines del siglo pasado cuando aludía a gobiernos de ámbito nacional hasta la actualidad, donde debemos analizarlo en los contextos globales. En estos, asimismo, se excluyó totalmente la posibilidad de participación de los ciudadanos y sus instituciones primarias, ya que se trata de superestructuras que, además, poco tienen en cuenta la opinión de los ciudadanos de a pie.

\footnotetext{
${ }^{12}$ O'Donnell, Guilermo, Disonancias: críticas democráticas a la democracia, Buenos Aires, Prometeo, 2007, p. 99.

${ }^{13}$ Utilizamos el término gobernabilidad alli donde el Banco Mundial habla de governance, dado que gobernanza es una condición que supone una participación más comprometida de los ciudadanos en la acción de gobierno con mecanismos de participación que no están presentes en las definiciones del Banco Mundial. En contraste, gobernabilidad alude a la posibilidad de alcanzar los objetivos gubernamentales sin mayores conflictos y con la satisfacción y el agrado de la mayoría de la población.
} 
Inicialmente, las definiciones de gobernabilidad del Banco Mundial eran muy restringidas. Se constreñían a señalarla como el ejercicio del poder político para conducir los asuntos de la nación. Igualmente, al presentar las propiedades que deben caracterizar una buena gobernabilidad, los elementos que propone el Banco Mundial son más limitados que los de otros autores. Vivien Collingwood ${ }^{14}$ incluye ocho componentes (transparencia y accountability, respeto al Estado de derecho, aplicación de medidas y acciones contra la corrupción, democratización, reformas a los gobiernos locales, descentralización de la gestión y toma de decisiones en el ejercicio del gobierno, incremento de la participación de la sociedad civil y respeto a los derechos humanos y al medio ambiente).

En cuanto al Banco Mundial, la lista se reduce a seis: opinión y accountability, estabilidad política y ausencia de violencia política y terrorismo, efectividad gubernamental, calidad regulatoria, Estado de derecho y control de la corrupción. ${ }^{15}$ Es evidente que la definición de gobernabilidad que actualmente proporciona el Banco Mundial es más amplia, ya que la define como el conjunto de tradiciones e instituciones por las cuales se ejerce la autoridad en un país. Éstas incluyen: el proceso por el cual se eligen, supervisan y sustituyen gobernantes; la capacidad del gobierno para formular e implementar de manera efectiva las políticas demandadas por la opinión pública; y el respeto de los ciudadanos y el Estado por las instituciones del gobierno y sus interacciones recíprocas.

Esto último nos acerca a algunas de las ideas de 0'Donnell. Nuestra percepción es que, de todos modos, el Banco Mundial es ajeno a las necesidades y demandas de los ciudadanos. La capacidad para asegurar el compromiso de la ciudadanía en la acción gubernamental es esencial para asegurar una buena gobernanza.

Debemos reconocer que el Banco Mundial, a partir del año 2004, al comentar las características y condiciones de la accountability social, a la que nos referiremos inmediatamente, introdujo la idea de dar voz y poder a los pobres. ${ }^{16}$

138 Esto fue un giro notable en la ideología de la institución, que hasta ese momento no había mostrado ninguna sensibilidad por las necesidades de la población y menos por las de sus sectores más desfavorecidos.

\footnotetext{
${ }^{14}$ Colungwood, Vivien, Good governance and the World Bank, Reino Unido, University of Oxford, 2003, p. 2.

15 Kaufmann, Daniel, Kraay, Aart, y Mastruzzi, Massimo, "The Worldwide Governance Indicators: Methodology and Analytical Issues", 2010. [Consulta: 24 de abril, 2017]. Disponible en: http://info.worldbank.org/

${ }^{16}$ Malena, Carmen, Forster, Reiner y Singh, Janmejay, "Social accountability. An Introduction to the concept and Emerging Practice", World Bank, Social Development Papers, núm. 76.
} 
Catalina Smulovitz y Enrique Peruzzotti ${ }^{17}$ han propuesto una tipología para la accountability que se muestra en la tabla 1. Distinguen entre los agentes (¿quién controla?) y los mecanismos de control político y burocrático. Por otro lado, dividen la accountability en horizontal y vertical; y esta última, a su vez, en electoral y societal. ${ }^{18}$ En cuanto a los mecanismos de control, se incluye una gran cantidad en diferentes niveles, ampliando la consideración de agentes y factores. Es decir, los mecanismos de control, aun cuando sean originados en agencia individual, son instituciones de la sociedad en su conjunto. El énfasis está dado porque en la filosofía liberal, el ciudadano es un elemento aislado frente al Estado, mientras que aquí actúa conjuntamente con otros y por ello obtiene mayor poder.

Tabla 1. Tipos de accountability

\begin{tabular}{|c|c|c|c|}
\hline & ¿Quién controla? & $\begin{array}{l}\text { Mecanismos para el } \\
\text { control político }\end{array}$ & $\begin{array}{l}\text { Mecanismos para el control } \\
\text { burocrático }\end{array}$ \\
\hline $\begin{array}{l}\mathrm{H} \\
\mathrm{o} \\
\mathrm{r} \\
\mathrm{i} \\
\mathrm{z} \\
\mathrm{o} \\
\mathrm{n}\end{array}$ & Ejecutivo & Veto & $\begin{array}{l}\text { Fijación de la política } \\
\text { Regulación } \\
\text { Supervisión administrativa } \\
\text { Nombramiento y remoción } \\
\text { de personal }\end{array}$ \\
\hline $\begin{array}{l}\mathrm{t} \\
\mathrm{a} \\
\mathrm{l}\end{array}$ & Legislativo & $\begin{array}{l}\text { Proceso de destitución } \\
\text { Comisión investigadora } \\
\text { Veto de anulación }\end{array}$ & $\begin{array}{l}\text { Fijación de la política } \\
\text { Regulación } \\
\text { Supervisión administrativa } \\
\text { Nombramiento y remoción } \\
\text { de personal }\end{array}$ \\
\hline & Judicial & Revisión judicial & Revisión judicial \\
\hline & $\begin{array}{l}\text { Agencias } \\
\text { supervisoras }\end{array}$ & $\begin{array}{l}\text { Capacidad de } \\
\text { aplicación } \\
\text { Capacidad de } \\
\text { investigación }\end{array}$ & $\begin{array}{l}\text { Capacidad de aplicación } \\
\text { Capacidad de investigación }\end{array}$ \\
\hline
\end{tabular}

\footnotetext{
${ }^{17}$ Smulovitz, Catalna y Peruzzott, Enrique, "Societal Accountability in Latin America", Journal of Democracy, vol. 11, núm. 4, pp. 147-158.

${ }^{18}$ Hemos preferido mantener el término "societal" (aunque de uso raro en español) porque tiene el mismo significado que en inglés: se refiere a la sociedad en su conjunto, mientras que la expresión social está más referida a las interacciones entre personas y no a una entidad total como la sociedad.
} 


\begin{tabular}{|c|c|c|c|c|}
\hline & $\begin{array}{l}\mathrm{E} \\
\mathrm{l} \\
\mathrm{e} \\
\mathrm{c} \\
\mathrm{t} \\
\mathrm{o} \\
\mathrm{r} \\
\mathrm{a} \\
\mathrm{l}\end{array}$ & $\begin{array}{l}\text { Partidos políticos } \\
\text { con representación } \\
\text { parlamentaria }\end{array}$ & $\begin{array}{l}\text { Representación política } \\
\text { Fijación de la política }\end{array}$ & $\begin{array}{l}\text { Regulación } \\
\text { Fijación de la política }\end{array}$ \\
\hline $\begin{array}{l}\mathrm{V} \\
\mathrm{e} \\
\mathrm{r} \\
\mathrm{t} \\
\mathrm{i} \\
\mathrm{c} \\
\mathrm{a} \\
\mathrm{l}\end{array}$ & $\begin{array}{l}\text { S } \\
\text { o } \\
\mathrm{c} \\
\mathrm{i} \\
\mathrm{e} \\
\mathrm{t} \\
\mathrm{a} \\
\mathrm{l}\end{array}$ & $\begin{array}{l}\text { Asociaciones } \\
\text { cívicas, } \\
\text { organizaciones no } \\
\text { gubernamentales } \\
\text { y movimientos } \\
\text { sociales } \\
\text { Ombudsman } \\
\text { Medios }\end{array}$ & $\begin{array}{l}\text { Movilización social y } \\
\text { exposición pública } \\
\text { Investigación por } \\
\text { agencias supervisoras } \\
\text { Ordenación de la } \\
\text { agenda } \\
\text { Denuncia } \\
\text { Pleito jurídico } \\
\text { Exposición y denuncia } \\
\text { pública } \\
\text { Ordenación de la } \\
\text { agenda }\end{array}$ & $\begin{array}{l}\text { Movilización social y } \\
\text { exposición pública } \\
\text { Investigación por agencias } \\
\text { supervisoras } \\
\text { Ordenación de la agenda } \\
\text { Denuncia } \\
\text { Pleito jurídico } \\
\text { Exposición y denuncia } \\
\text { pública } \\
\text { Ordenación de la agenda }\end{array}$ \\
\hline
\end{tabular}

Fuente: Adaptado de Smulovitz, Catalina y Peruzzotti, Enrique, "Societal Accountability in Latin America", Journal of Democracy, vol. 11, núm. 4.

Esta tipología introduce de facto la noción de accountability societal, que es otra categoría o tipo de accountability, que Guillemo 0’Donnell tomará en cuenta, de manera especial, a partir de reconocer la propuesta de Catalina Smulovitz y Enrique Peruzzotti. ${ }^{19}$ Se trata de mecanismos de control vertical que no tienen su origen en las instituciones o procesos electorales, sino que son la consecuencia de las acciones de los diferentes agentes de la sociedad civil y se insertan en el sistema gubernamental, favorecidos o no por el poder político.

\section{Características de la accountability societal}

La accountability societal, por lo tanto, no sería una condición o propiedad de las instituciones del Estado, sino de la sociedad civil. Más que un resultado de la

\footnotetext{
${ }^{19}$ Smulovitz, Catalna y Peruzzomi, Enrioue, "Societal Accountability in Latin America", Journal of Democracy, vol. 11, núm. 4, pp. 147-158; Peruzzomi, Enrique y Smulovitz, Catalina, Controlando la política. Ciudadanos y medios en las nuevas democracias latinoamericanas, Buenos Aires, Editorial Temas, 2002. O'Donnell, Guillermo, Disonancias: críticas democráticas a la democracia, Buenos Aires, Prometeo, 2007, p. 127.
} 
concepción liberal de la política, se trata de una consecuencia de la inclusión de un modelo republicano de la acción política y gubernamental, aun cuando para 0’Donnell ${ }^{20}$ sería la combinación de las tres grandes corrientes que confluyen en las poliarquías: la liberal, la democrática y la republicana. Este proceso ha surgido de manera casi espontánea de la acción de diversos agentes sociales, y hasta ahora no se había manifestado con asiduidad. Quizá pudo darse una situación similar en la dinámica de los gremios medievales, pero como la organización y composición del poder en esa formación social no tienen similitudes con nuestra sociedad capitalista, no nos parece adecuado hacer comparaciones.

Sin duda, los movimientos sociales y otras agencias cumplieron parcialmente con algunas de las funciones de la accountability vertical, pero la aparición de organismos electorales ciudadanos, las distintas instituciones de fiscalización controladas por los ciudadanos, como el ombudsman y demás, constituyen un panorama de la política totalmente novedoso. Para 0'Donnell, estas instituciones son necesarias en especial cuando la accountabiity horizontal encuentra obstáculos para desenvolverse sin restricciones o imperfecciones.

$\mathrm{El}$ aporte de 0'Donnell consiste en reconocer que las tres formas de $a c-$ countability están relacionadas y se complementan: cada una es imposible sin la otra. La relación se establece a través de los diversos media. Esta dinámica contribuye significativamente al desarrollo de la democratización. No debemos olvidar que una de las características fundamentales de una democracia es la de proporcionar protección a los ciudadanos contra las acciones arbitrarias de los agentes gubernamentales. Esta protección debe proporcionarse especialmente a los grupos minoritarios. ${ }^{21}$ De ahí la importancia de la accountability societal y su plataforma mediática. Tampoco debe olvidarse que la larga lucha por la implantación de sistemas democráticos tuvo como punto de partida la restricción y acotación del poder de los gobernantes.

Por otro lado, la evolución de las condiciones de gobernabilidad en la globalización ha introducido una variante que anula muchas de las posibilidades de esta accountability societal. Muchas de las decisiones importantes para las políticas nacionales son tomadas en organismos supranacionales que no asumen ninguna responsabilidad por sus consecuencias negativas y sus efectos en la población. Leonardo Morlino ${ }^{22}$ identificó como 'transferencia de responsabilidad' a esta circunstancia por la cual la accountability política, por cualquier decisión impopular, se transfiere de un nivel nacional a uno supranacional,

\footnotetext{
${ }^{20}$ O'Donnell, Guillermo, Disonancias: criticas democráticas a la democracia, Buenos Aires, Prometeo, 2007, p. 136.

${ }^{21}$ Tilly, Charles y Wood, LeSLey, Social movements 1768-2012, Boulder, Paradigm, 2013, p. 128.

${ }^{22}$ Morlino, Leonardo, "What is a 'good' democracy?", Democratization, vol. 11, núm. 5, 2004, p. 20.
} 
como ocurrió en varias oportunidades en la Unión Europea y en la Comisión Interamericana de los Derechos Humanos.

Lo anterior se contradice con la caracterización que el Banco Mundial pretende de la social accountability, donde enfatiza la capacidad de los ciudadanos para influir en el Estado y en los organismos que proporcionan los servicios públicos para dar respuesta a las necesidades de los ciudadanos. ${ }^{23}$ Para el Banco Mundial, la accountability societal encierra las iniciativas que se enfocan en los ciudadanos como destinatarios últimos y se basa en los principios de transparencia. Establece que los ciudadanos o el Estado pueden iniciar los mecanismos de la accountability societal, pero a menudo son demandados y operados desde las bases. Se reconoce que la accountability de las instituciones es uno de los tres mecanismos clave para el empoderamiento de los pobres. ${ }^{24}$ Pero esto no tiene ningún valor a la vista de las acciones de muchas agencias internacionales, incluido el mismo Banco Mundial.

\section{Vanguardia y Vigencia de la propuesta de GuIllermo O’Donnell}

O’Donnell caracterizó la acountability societal dentro de una sociedad activa y bien organizada cuyos agentes son "individuos, movimientos sociales, organizaciones formales o lo que sea". ${ }^{25}$ Dentro de ese "lo que sea" propuso de manera vanguardista el mayor desarrollo de una idea y diversos tipos de actividad que Enrique Peruzzotti y Catalina Smulovitz ${ }^{26}$ no elaboraron: el concepto hirschmaniano de voice. $^{27}$

En palabras del mismo Guillermo 0’Donnell esta propuesta se entiende como:

una voz que, como lo sugiere la metáfora de la verticalidad, se dirige desde la sociedad "hacia arriba", hacia el Estado. Me tienta por esto

${ }^{23}$ World BANK, "Social accountability and demand for good governance", World Bank. [Consulta: 5 de mayo, 2017]. Disponible en: http://www.worldbank.org/en/topic/socialdevelopment/brief/social-accountability

${ }^{24}$ WoRLD BANK, "Empowering people by transforming institutions: social development in World Bank operations", World Bank. [Consulta:4demayo, 2017]. Disponibleen:http://documents.worldbank.org/curated/en/563751468780547056/ Empowering-people-by-transforming-institutions-social-development-in-World-Bank-operations

${ }^{25}$ O'Donnel, Guillermo, "Acerca de varias acountabilities y sus interrelaciones" en Enrique Peruzzotti y Catalina Smulovitz (eds.), Controlando la política. Ciudadanos y medios en las nuevas democracias latinoamericanas, Buenos Aires, Editorial Temas, 2002, p. 96. Capítulo que después formó el capítulo cuatro del texto: O'Donnell, Guillermo, Disonancias: críticas democráticas a la democracia, Buenos Aires, Prometeo, 2007, pp. 135 y ss.

${ }^{26}$ Peruzzomi, Enrioue y Smulovitz, Catalina, Controlando la política. Ciudadanos y medios en las nuevas democracias latinoamericanas, Buenos Aires, Editorial Temas, 2002.

${ }^{27}$ Hirschmann, Albert, Exit, Voice and Loyalty. Responses to Decline in Firms, Organizations, and States, Cambridge, Harvard University Press, 1970. 
decir que la verticalidad de la accountability social tiene, tendenciosa e intencionalmente, un destino horizontalizado. ${ }^{28}$

Es decir, O'Donnell concibe que la accountability societal tiene un verdadero origen ciudadano y por ello una génesis vertical ascendente y un destino horizontal. Al mismo tiempo, advirtió que: "los agentes de accountability social no son los 'grupos de presión', 'grupos de intereses' o instituciones 'neocorporativas', ${ }^{29}$ sino, precisamente, los ciudadanos.

Ahora bien, si el corazón de la accountability societal es una sociedad activa, bien organizada y con eficacia en la horizontalización de sus demandas, entonces cabe cuestionar por las condiciones que detonarán la participación ciudadana. Esas condiciones de participación impactan a la organización democrática de la ciudadanía (al margen del régimen de gobierno al que se le pide la rendición de cuentas) y también apuntan a cumplir las garantías de la horizontalización con el poder suficiente que hará cumplir a los Estados con la rendición de cuentas. La novedosa y atrevida propuesta de 0’Donnell, como toda visión vanguardista, abrió nuevos retos.

Para movilizar y organizar a la sociedad con miras a horizontalizar las exigencias de la accountability, O'Donnell elucidó una agenda de investigación. En el núcleo de esa agenda, se complementan los alcances que no habían conseguido Smulovitz y Peruzzotti. ${ }^{30}$ O’Donnell la concibió como: “alguna combinación de tiempo, información, acceso a media, capacidad de comunicación pública e interpersonal". ${ }^{31}$ La combinación de estos elementos constituye la calidad vanguardista de 0'Donnell.

Sin precisar sobre el referente combinatorio de tiempo, O’Donnell tiene bien sabido que el ciudadano común no posee tiempo suficiente para atender la complejidad y especialización de los asuntos públicos. Sin embargo, en la actualidad, gracias a las nuevas tecnologías de información y comunicación se puede contar con las dimensiones del tiempo virtual y el tiempo real que permiten diversas combinaciones entre sí y, lo que es más importante, la combinación entre el tiempo privado del ciudadano y su tiempo público.

En particular, el tiempo privado (en el cual un sector de ciudadanos puede verse afectado por la falta de transparencia y rendición de cuentas

\footnotetext{
${ }^{28}$ O'Donnel, Guillermo, "Acerca de varias acountabilities y sus interrelaciones", Controlando la política, p. 96.

${ }^{29}$ O'Donnel, Guillermo, "Acerca de varias acountabilities y sus interrelaciones", Controlando la politica, p. 95.

30 Smulovitz, Catalna, y Peruzzotil, Enrioue, "Societal Accountability in Latin America", Journal of Democracy, vol. 11, núm. 4, 2000, pp. 147-158.

${ }^{31}$ O'Donnel, Guillermo, "Acerca de varias acountabilities y sus interrelaciones", Controlando la política, p. 97.
} 
gubernamentales) y el tiempo público (otro grupo de ciudadanos con mayor capacidad, información y experiencia sobre el o los asuntos públicos) pueden vincularse para que el segundo atienda solidariamente al primero. Los ciudadanos con mayor experiencia sobre los asuntos públicos no son representantes políticos de oficio, ni miembros de partidos políticos, sino ciudadanos individuales, asociaciones civiles, organizaciones no gubernamentales, colectivos de movimientos sociales, plataformas ciudadanas y medios de comunicación. El interés general y el bien común, aunado a los intereses particulares de los afectados o vulnerables y junto con las posibilidades de las contemporáneas tecnologías, causan y encausan la combinación de tiempo real y virtual, privado y público, que O'Donnell vislumbró para hacer eficientes a las exigencias de la rendición de cuentas gubernamental.

En lo referente a la información, el acceso a media y la capacidad de comunicación pública e interpersonal, 0’Donnell se cuestionó las dificultades. Éstas pueden clasificarse en dos dimensiones: la política y la comunicativa. De la primera advirtió que la agenda de investigación debe indagar la trayectoria de las demandas de accountability societal originadas desde los sectores socialmente débiles, excluidos o desprotegidos en el sentido de los recursos, estrategias y puntos de acceso de oclusión en el Estado que permitirían acciones prósperas, firmes o duraderas para generar bienes públicos o, al menos, para los sectores en movilización.

De la dimensión comunicativa, O'Donnell indicó que habría que indagar qué tipo de medios recogen dichas acciones y qué consecuencias pueden preverse. Podría añadirse más aún: en la dimensión comunicativa, no sólo recae el reto de informar, acceder a los media y lograr la exposición pública y la comunicación interpersonal, sino horizontalizar la exigencia de la transparencia y la rendición de cuentas, que es la acción decisiva de la accountability societal. Es decir, empoderar al ciudadano no sólo frente o ante el Estado, sino dentro y en el Estado mismo.

Horizontalizar la accountability societal es el reto de máxima importancia comunicativa por sus efectos políticos. Peruzzotti y Smulovitz parecen 144 conformarse con desatar escándalos mediáticos que hacen pública a la corrupción. ${ }^{32}$ Limitan a los medios de comunicación a la mera exposición del cobro de costos reputacionales con un incierto efecto institucional en la política. ${ }^{33}$ Los costos reputacionales generalmente son saldados con la interrupción de las

\footnotetext{
32 Peruzzomi, Enrloue y Smulovitz, Catalna, "Accountability social: la otra cara del control" en Controlando la política. Ciudadanos y medios en las nuevas democracias latinoamericanas, Enrioue Peruzzott y Catalna Smulovitz (eds.), Buenos Aires, Editorial Temas, 2002, p. 23.

${ }_{33}$ Peruzzoti, Enrioue y Smulovitz, Catalina, "Accountability social: la otra cara del control" en Controlando la política, p. 35.
} 
trayectorias de los funcionarios públicos individualizados pero no impactan a las instituciones políticas en general o a la condición del Estado.

Los costos reputacionales por sí mismos no son suficientes. No basta con el "escándalo" político, sino, como atinadamente indica Elgueta, ${ }^{34}$ se requiere que los mecanismos de la accountability societal alteren el capital simbólico en el campo político. A falta de sanciones formales, los medios puedan recaudar sanciones simbólicas. Ello es posible en la medida que la movilización mediática gesta el capital social e influye en la agenda pública.

A pesar del pesimismo de Shugart, Moreno y Crisp, ${ }^{35}$ basado en los principios del presidente estadounidense James Madison, que consideran que la accountability horizontal falla por los defectos e ineficiencias de la accountability vertical no electoral (es decir, la societal), Peruzzotti y Smulovitz creen en la posible activación de la accountability horizontal porque los reclamos "llegan a los medios, o los medios llegan a ellos"36 y los medios logran constituirse como "fiscales y jueces" que llaman la atención de las autoridades, juzgan informalmente las actividades ilegales y aceleran las decisiones públicas.

Pero para combatir el pesimismo político no basta con el optimismo mediático y "la política del avergonzamiento", pues los media tienen intereses económicos, políticos y constituyen un poder corruptible o influenciable. Sin embargo, la propuesta de 0’Donnell mantiene su vigencia porque rebasa la condición histórica de los medios en que fue creada. Los mass media también tuvieron su propio desarrollo democratizador, su empoderamiento hacia la horizontalidad. Habermas ${ }^{37}$ describe el inicio de este empoderamiento cuando apunta que los medios dejaron de pensarse como "prensa de noticias", para considerarse como "prensa de opinión”. O’Donnell advirtió esa inercia y visualiza que los medios adquirieron la posibilidad de expandirse como prensa de propuesta, ejercicio, revisión y ampliación de asuntos públicos.

La evolución de los media, aún en cuanto meros instrumentos tácticos, tiene un giro democrático aún vigente que O’Donnell enfatizó: la horizontalización de la accountability societal es posible más allá de la división relativamente

\footnotetext{
${ }^{34}$ Elgueta, Raúl, "Resención de Peruzzotti, Enrique y Catalina Smulovitz (eds.). 2002. Controlando la política: ciudadanos y medios en las nuevas democracias. Buenos Aires: Editorial Temas, 325 pp.", Revista de Ciencia Política, vol. 23, núm. 2, 2003, p. 287.

35 Shugart, Matthes, Moreno, Erika y Crisp, Brian, "The Accountability Deficit in Latin America" Presentada en la reunion sobre "Institutions, Accountability, and Democratic Governance in Latin America," Kellogg Institute for International Studies, University of Notre Dame, Notre Dame, Indiana, May 8-9, 2000. [Consulta: 7 de agosto, 2017]. Disponible en: https://www3.nd.edu/ kellogg/faculty/research/pdfs/Shugart.pdf

${ }^{36}$ Peruzzomi, Enrique y Smulovitz, Catalina, "Accountability social: la otra cara del control", en Controlando la política, p. 38.

${ }^{37}$ Habermas, Jurgen, Historia y crítica de la opinión pública, Barcelona, Ediciones G. Gili, 2007, p. 209.
} 
autónoma y equilibrada de poderes, de la responsabilidad y honestidad de las agencias de accountability horizontal, del poder repartido en el modelo federalista o de las legislaturas con la modalidad bicameral, porque los derechos civiles mínimos hallan expresión y defensa en la actividad que los media permiten con la interpenetración parcial entre los poderes fácticos. ${ }^{38}$ Sin duda 0'Donnell se refiere, con su propio vocabulario al señalar la horizontalización, a los conceptos contemporáneos de gobernanza y de gobierno abierto que hacen eficaz la transparencia y el ejercicio de rendición de cuentas.

Lamentablemente la condición histórica y geográfica de la accountability, como objeto de estudio en América Latina, que acaparó la atención de O’Donnell, no le permitió explorar al máximo las estrategias de su propuesta de horizontalización a través del poder de facto que poseen los medios. Esa limitante se debió a que la movilización mediática (aún para Habermas o para Castells,$^{39}$ contemporáneos de 0'Donnell) no alcanzaba en esos momentos de su desarrollo a cumplir con el deseo democrático. No obstante, frente a la prueba histórica de la evolución de las nuevas tecnologías de la comunicación y la información, la propuesta de 0’Donnell airosamente conserva su vigencia.

\section{LA ACCOUNTABILITY SOCIETAL A PRUEBA EN LOS NEW MEDIA}

La accountability societal no se reduce a la simple exigencia de diversos sectores de la sociedad sobre la transparencia y rendición de cuentas por parte de las autoridades. O’Donnell insistió en que la accountability societal no tiene prioritariamente un interés material en el sentido de restituir a los ciudadanos los recursos que las autoridades no utilizaron bien; su misión principal es el ajuste legal de las actuaciones del gobierno. Es decir, la principal demanda de la accountability societal es la solicitud de respeto a diversos derechos civiles y que las acciones gubernamentales resulten apegadas a la legalidad. ${ }^{40}$ Gracias a ello, los actos de gobierno obtendrán legitimidad.

En ese contexto, 0’Donnell se pregunta “cómo y cuándo los medios (y qué 146 tipo de medios) recogen o no estas acciones [las acciones del Estado y sus interacciones con los ciudadanos al horizontalizar la accoutability] y cuáles son las consecuencias". ${ }^{41}$ Pero la cuestión de interés trascendente no estriba en el tipo

\footnotetext{
${ }^{38}$ O'DonnelL, Guilermo, "Accountability horizontal: la institucionalización legal de la desconfianza política", POSTData, Revista de Reflexión y análisis político, núm. 7, 2001, p. 7.

${ }^{39}$ Castells, Manuel, La Galaxia Internet, España, Plaza y Janés, 2001, p. 177.

${ }^{40}$ O'Donnel, Guillermo, "Acerca de varias accountabilities y sus interrelaciones" en Controlando la política, p. 95.

${ }^{41}$ O'donnel, Guilermo, "Acerca de varias accountabilities y sus interrelaciones" en Controlando la política, p. 97.
} 
de medios o sus tácticas, porque los medios están en constante transformación. La cuestión es mostrar que la propuesta democratizadora de nuestro autor está vigente y que la actual era digital de las nuevas tic la validan y también pueden potenciarla. Ello se evidencia en dos dimensiones: el tipo de democracia que la accountability societal alcanza con las TIc, es decir, una democracia con gobernanza; y la veracidad de dicha horizontalización al mostrar la evolución y comparación de los mass media tradicionales con los new media en clave societal, de gobierno abierto y de gobernanza.

El primer aspecto se aplica concibiendo la accountability societal de manera simultánea a diversas acciones de gobierno y no sólo como un "informe o reporte” una vez que el gobierno actuó. La simultaneidad de la accountability societal que habilita la horizontalización se encuentra, por ejemplo, en la propuesta de Jan Van Dijk, denominada democracia libertaria y concebida como democracia plebiscitaria, ${ }^{42}$ inspirada en la autonomía democrática de Held, ${ }^{43}$ en que postula a la participación ciudadana permanente para convocar y ejecutar plebiscitos a través de las Tic. De esta manera, se elimina el monopolio gubernamental de los representantes políticos y se genera un proceso validante o correctivo de gobernanza.

Respecto a la segunda dimensión, la accountability societal muestra que la gobernabilidad es legal cuando se atiene a las decisiones procedimentales dentro del derecho y justifica su legitimidad cuando posee la interacción comunicativa entre los ciudadanos que, ejerciendo su libertad de expresión, pueden manifestar su satisfacción. Pero en el caso de déficits políticos y representativos, dicha legitimidad requiere ser compensada por vía de la gobernanza. La noción de gobernanza es polisémica porque alude a un nuevo estilo de gobierno que deja atrás el control jerárquico y las condicionantes del mercado. Se caracteriza por una mayor interacción y cooperación entre el Estado y los actores no estatales. Horizontalizar la rendición de cuentas, que inicia con un origen vertical ascendente, es un modo de gobernanza que lleva al gobierno a dar cuenta y razón de sus acciones junto con los ciudadanos que en él intervienen. De este modo, los actores estatales y no estatales están involucrados en redes sociales que fluctúan entre lo público y lo privado y al interactuar entre sí impiden que el Estado sea la instancia única de gobierno para tomar decisiones y ejercer sus disposiciones. Así, las tareas del gobierno son completadas, fiscalizadas, corregidas o auxiliadas por instancias ajenas al Estado. Por

\footnotetext{
42 VAN DIJk, JAN, "Models of Democracy and Concepts of Communication", K. Hacker and J. van Dijk (eds.), Digital Democracy. Issues of Theory and Practice, London, New Delhi, Sage, 2000, pp. 30-53.

${ }^{43}$ HeLD, DAVID, Modelos de democracia, Madrid, Alianza, 1991.
} 
tanto, la gobernanza no sigue las escalas gubernamentales o sociales, sino la interacción de redes autónomas que hacen referencia a estructuras y procesos de información, enlace y decisión.

Ahora bien, la gobernanza no sólo tiene efectos o funciones de legitimación, sino que permite el tránsito de la gobernabilidad al autogobierno en la medida en que no inhibe la formación de redes políticas y promueve su intervención. Por ende, cambia el equilibrio entre el Estado y la ciudadanía, rompe los modelos fijos de organización política y promueve la condición más adaptable a los requerimientos y los espacios de participación. Debe insistirse en que las redes promovidas por la gobernanza serán más eficientes en la medida en que adoptan la instrumentalización de los medios de comunicación que apuntala la democracia electrónica.

Las redes sociales que gestiona la gobernanza, en opinión de Natera, requieren tres disposiciones para evitar el monopolio de las decisiones: "su ordenación elemental, mediante el incremento del número y diversidad [...] la distribución del poder en su interior [...] y el espacio de las percepciones". ${ }^{44}$ Para conseguir estas características, es deseable que devengan redes sociales cibernéticas, pues internet posee los instrumentos necesarios para estructurar estas estrategias. En consecuencia, la accountability societal, ejercida como gobernanza, posee mayor capital social y capacidad de participación ciudadana que la mera gobernabilidad; en consecuencia, equilibra el acceso al poder. Con ello, busca nivelar a favor de la esfera privada el balance que asimétricamente poseen las dimensiones pública y política que muchas veces los medios tradicionales de comunicación cooptaron junto con la oligarquía de partidos.

En la tabla 2 pueden compararse, en razón de la participación ciudadana, la gobernabilidad y la gobernanza.

${ }^{44}$ Natera, Antonio, "Nuevas estructuras y redes de gobernanza", Revista Mexicana de Sociología, vol. 67, núm. 4, 2005, p. 774. 
Tabla 2. Comparación entre gobernabilidad y gobernanza

\begin{tabular}{|l|l|}
\hline \multicolumn{1}{|c|}{ Gobernabilidad } & \multicolumn{1}{c|}{ Gobernanza } \\
\hline $\begin{array}{l}\text { Institucionalización estatal que coopta la } \\
\text { participación ciudadana }\end{array}$ & $\begin{array}{l}\text { Participación ciudadana directa en asuntos } \\
\text { públicos }\end{array}$ \\
\hline $\begin{array}{l}\text { Verticalidad estatal aún en la consulta } \\
\text { ciudadana }\end{array}$ & $\begin{array}{l}\text { Conducción democrática por los consensos } \\
\text { deliberativos no jerarquizados }\end{array}$ \\
\hline $\begin{array}{l}\text { Condicionamientos normativos del Estado } \\
\text { a la ciudadanía y sus redes }\end{array}$ & $\begin{array}{l}\text { Simetrías entre Estado, ciudadanos y redes } \\
\text { sociales }\end{array}$ \\
\hline Acción pública exclusiva del Estado & $\begin{array}{l}\text { Aceptación de redes en cooperación o } \\
\text { delegación de acciones estatales }\end{array}$ \\
\hline $\begin{array}{l}\text { Gestión insuficiente porque las } \\
\text { jurisdicciones públicas no pueden abarcar } \\
\text { monopólicamente la especialidad y } \\
\text { competencias para enfrentar los problemas } \\
\text { transversales }\end{array}$ & $\begin{array}{l}\text { No hay monopolio del poder, pues se } \\
\text { ubica en la interacción del poder público, } \\
\text { la iniciativa privada y la participación } \\
\text { ciudadana que permiten la transversalidad } \\
\text { del conocimiento y sus soluciones }\end{array}$ \\
\hline
\end{tabular}

Fuente: elaboración propia con datos de Paniagua, Abraham, José Borunda e Ignacio Camargo, "Transparencia, participación ciudadana y gobierno electrónico: el caso del gobierno local de Ciudad Juárez, México”, Sociedade e Cultura, año 15, núm. 1 .

Las redes ciudadanas construidas por la gobernanza son, literal y etimológicamente, cibernéticas, en tanto recuperan el arte de gobernar.

Es necesario entonces revisar los nuevos medios de información y comunicación (Facebook, Twitter, E-mail, Wikis) y compararlos con los medios tradicionales. Se trate de una plataforma electrónica o de una red social cibernética, las diferencias son marcadas con los mass media tradicionales (radio, cine, televisión y periódicos), e inclusive con la versión Web 1.0. En las redes sociales cibernéticas los usuarios pueden ser a la vez receptores y emisores, mientas que en los medios tradicionales los usuarios sólo podían tener el rol de receptores. Ello propiciaba la "colonización" del Estado o la imposición de la esfera pública en la privada en términos de los intereses de los medios. La mayor libertad de los nuevos medios obedece a que no están sujetos a la economía del mercado o la reelección política, pues en la medida en que la tecnología avanza, proceden del software libre y utilizan todo tipo de contenidos no comprometidos.

Las redes sociales cibernéticas prácticamente carecen de barreras de ingreso toda vez que se posee una conexión a internet. El acceso a internet es una demanda que cada vez se cumple en mayor medida por mandato del Estado en los lugares públicos o por vía de autorización de concesiones a los proveedores particulares. La información y deliberación en las redes cibernéticas se propagan en "tiempo real"; por tanto, son más libres de censura que los medios tradicionales. 
Los nuevos medios también carecen de compromisos clientelares porque cada usuario a la vez es un protagonista y un receptor. Mientras que en los medios de comunicación tradicionales sólo los emisores son protagonistas, en la radio un sólo sujeto habla y muchos escuchan, en la pantalla de televisión o del cine unas cuantas personas aparecen y muchas contemplan, en los periódicos casi siempre escriben los mismos editorialistas o reporteros y la audiencia apenas tiene un espacio insignificante en "cartas al editor" o "los lectores opinan".

No sucede así en las Web 2.0 y 3.0, que se comportan con independencia de la cantidad de receptores y cada usuario incrementa exponencialmente su valor, tanto comercial como social y político. Cualquiera que lo desee puede subir un tuit o video, una publicación o un texto enciclopédico wiki e inclusive participar en la wiki-legislación. La Constitución Ciudadana de Islandia, aprobada por un referéndum de octubre de 2012 (según la relatoría del Partido Comunista Obrero Español $)^{45}$ y pendiente de autorización por el parlamento electo en 2016 y que estará en funciones hasta 2019, es un ejemplo mundial de cómo una plataforma electrónica de participación y cooperación logra que la accountability societal devenga en horizontal. En dicha plataforma participó una muestra obtenida por sorteo del universo de ciudadanos voluntarios.

En los mass media tradicionales, la mayoría de las ocasiones la información estratégica está vertida de manera parcial, en lenguaje técnico e intencionalmente ininteligible para quienes no pertenecen a las elites de la tecnocracia. Mientras en los new media casi siempre la información se difunde en lenguaje estándar, democratizando las ideas o, en el caso de nociones complejas, aclarándolas una y otra vez en su difusión al grado de general tutoriales de aplicación y acciones ejecutivas.

Los medios masivos tradicionales sólo tienen el alcance de su propio medio de difusión (regional, nacional, continental o internacional, según su naturaleza). En contraste, los new media permiten que los mensajes se visualicen, técnicamente hablando, desde cualquier parte del mundo a una velocidad vertiginosa.

El vértigo comunicativo de las redes sociales cibernéticas y las plataformas 150 electrónicas también obedece a una estructura no condicionada por la secuencialidad, pues se opera en forma discrecional. Esto conlleva el riesgo de excesos y desorden en las comunicaciones. En contraparte, los medios tradicionales, tanto por la censura, la limitación y los compromisos clientelares y de mercado, manifiestan sus mensajes de manera secuencial y seleccionada. Por ello, requieren del

\footnotetext{
45 Partido Comunista Obrero Español, Islandia: radiografía de una revolución "ciudadana», 2013. [Consulta: 19 de mayo, 2017], Disponible en: http://www.pcoe.net/actualidad1/actualidad-internacional/444-islandia-radiografia-de-una-revolucion-ciudadana
} 
público como su aval y necesitan someterse a certificaciones estandarizadas de calidad para conservar su credibilidad. En contraste, los new media, al carecer de censura y de necesidad de aval, multiplican los enlaces en red a pesar de llegar a carecer de fuentes de credibilidad que sustenten sus contenidos.

La interactividad de las redes sociales cibernéticas es un bien comunicativo, dado que, por sí misma, mejora al contenido, al medio y al usuario. Su multilateralidad contrasta con la unilateralidad de los medios tradicionales que tienden a sesgar la visión sobre el Estado. A diferencia de los medios tradicionales que sólo buscan la utilidad receptiva, las redes sociales cibernéticas enriquecen la ciudadanía con la inclusión, la definición de identidades diferenciadas y la determinación de nuevos actores. Mientras los medios tradicionales homogeneizan sus audiencias, las redes cibernéticas ponen en emergencia la diversidad minimizando cualquier centralización. Con ello, promueven la multiculturalidad, el pluralismo, la criticidad y la evaluación, elementos indispensables para ejercer una adecuada accountability. No obstante, existe un problema que va en aumento: el uso de las redes sociales cibernéticas para la divulgación de noticias falsas.

La falsedad en política ha estado presente desde la antigüedad. En el libro II de República, Platón reflexiona sobre las mentiras en dioses y humanos; aun condenándola, admite que la mentira aparece como normal en muchas conductas de ambos. ${ }^{46}$ En De principatibus, Niccolò Machiavelli ${ }^{47}$ aconseja al gobernante "ser gran simulador y disimulador; los hombres son tan simples y obedecen tanto a las necesidades presentes, que aquél que engaña encontrará siempre quien se deje engañar".

Más modernamente, Hannah Arendt ${ }^{48}$ expresaba que la verdad y la política nunca se llevan bien, y siempre se ha visto a la mentira como una actividad necesaria para los políticos y para el hombre de Estado. La novedad de la época actual, con la llamada posverdad, es que la apariencia de verdad se convierte en más significativa que la verdad en sí misma. El problema, como señalara Foucault, ${ }^{49}$ es el de la verdad cooptada por el poder y el sistema de verdad de cada sociedad que define como verdaderos a sus discursos y, al mismo tiempo, los modos de la apariencia por los cuales un discurso puede aparecer como verdadero o como falso. Foucault establece dos proposiciones: "Por 'verdad' hay que entender un conjunto de procedimientos reglados por la producción,

\footnotetext{
${ }^{46}$ Platón, Diálogos IV., República, Madrid, Gredos, 2008, pp. 135-146.

${ }^{47}$ Machiaveluı, Niccolò, De principatibus (El príncipe), México, Trillas, 1999, p. 249.

${ }^{48}$ Arendt, Hannah, Entre el pasado y el futuro, Barcelona, Península, 1996, p. 239.

${ }^{49}$ Foucault, Michel, Obras esenciales, volumen II. Estrategias de poder, Barcelona, Paidós, 1999, p. 53.
} 
la ley, la repartición, la puesta en circulación, y el funcionamiento de los enunciados"; "La 'verdad' está ligada circularmente a los sistemas de poder que la producen y la mantienen, y a los efectos de poder que induce y que la acompañan, al 'régimen' de verdad. ${ }^{50}$

Como dice Enrique Carpintero, ${ }^{51}$ la mentira es una acción verbal, de carácter intencional y que pertenece al registro consciente de la actividad. Señala cuatro propiedades: una conciencia en el hablante sobre lo que es verdadero; la conciencia sobre el carácter incierto de aquello que se dice; la intención de engañar, y la intención del hablante de ser tomado como veraz. Pero no todas las mentiras se explican por este modelo, porque pueden existir identificaciones no conscientes donde se produce la mentira.

Lo peligroso de la situación actual es la posverdad asumida por un sujeto sin confrontar con los pares de su medio. Además, recurre a las redes cibernéticas para compartir sus ideas con otros que piensan de manera similar, con lo cual refuerza su posición y obtiene una sensación de seguridad inadecuada. Los mass media influyen en ciudadanos no informados, pues los expertos con supuesta credibilidad o las expresiones retóricas de personalidades construidas como públicas o líderes de opinión marcan tendencias con sus juicios de valor. Cosa muy diferente pasa en los new media, pues generalmente no se expresan con posiciones mesuradas hacia la audiencia de electores; no desean manipular porque difaman o enaltecen a los actores o instituciones gubernamentales con sus propias evidencias.

Para agregar un elemento de intranquilidad, la divulgación de datos que prueban la participación de la Internet Research Agency (IRA) (organismo respaldado por el Kremlin que se dedica a desinformar a escala global y que ha intervenido en las noticias difundidas en la red con ocasión de las recientes elecciones estadounidenses, el Brexit del Reino Unido en Europa, el conflicto interno en Cataluña y otros acontecimientos mundiales), ${ }^{52}$ han aumentado las sospechas y dudas sobre el uso de las redes con objetivos democráticos. Los bots (cuentas automatizadas) producen una sensación incorrecta, induciendo a las personas a creer en llamadas y anuncios falsos, compartiéndolos y difundiéndolos, creando la ilusión de una opinión mayoritaria y engañando a los votantes con la ilusión de mantener opiniones bien informadas.

\footnotetext{
${ }^{50}$ Foucault, Michel, Obras esenciales, volumen II. Estrategias de poder, Barcelona, Paidós, 1999, p. 55.

${ }^{51}$ Carpintero, Enrioue, "El concepto de "posverdad": una nueva mentira", Revista Topía. Disponible en: https://www. topia.com.ar/articulos/concepto-posverdad-una-nueva-mentira

${ }^{52}$ SALAS, JAVIER, "La gran cizaña de los 'bots' de Internet", El País, año XLI, núm. 14749, 24 noviembre 2017, p. 24.
} 
Aunado a lo anterior, las plataformas y las redes sociales cibernéticas generan nuevos derechos y se apropian de ellos al exigir educación electrónica, gestión gubernamental electrónica (trámites de la administración pública, voto electrónico y, por supuesto, auditorias y fiscalización sobre los datos de gobierno abierto, entre otros modos de participación ciudadana electrónica). $\mathrm{Su}$ intención no es inducir al usuario hacia la búsqueda de información para hacerle suponer que posee la democracia, sino que difunden ideas, le obsequian la información y provocan la deliberación para construir la democracia. Precisamente la comunicación pública e interpersonal señalada por O’Donnell, que, sin lugar a dudas, acredita la prueba del tiempo evolutivo de los medios.

\section{Conclusiones}

Si O’Donnell preguntó en su agenda de investigación cómo, cuándo, qué medios y cuáles consecuencias eran causadas por las acciones de laaccountability societal que provocaban los medios, puede decirse que existen elementos suficientes para aprobar su noción de accountability por el uso efectivo tanto de los medios tradicionales como de los nuevos, con sus respectivos efectos democratizadores.

Respecto a cómo puede responderse con algunas de las expresiones más significativas que las redes cibernéticas contemporáneas tomaron del mundo de la biología: la acción viral de la comunicación y el proceder colectivo de la ciudadanía como enjambre. La acción viral concebida como la propagación exponencial de la información en tiempo real, superando cualquier tipo de censura y construyendo tendencias (trending topics) que se insertan en la agenda pública y obligan a las agencias horizontales de control a revisar las acciones denunciadas.

Esta propagación se hace entre ciudadanos para construir una conciencia de red no dispuesta en organizaciones constituidas, ni en identidades o intereses comprometidos con vínculos fuertes. El enjambre social es un comportamiento de redes donde no todas las personas se conocen entre sí, no poseen autoridad central o mando implícito y no funcionan estructuradamente bajo jerarquías o protocolos de autoconservación (como ocurre con los partidos políticos, sindicatos y algunos movimientos sociales).

En los enjambres, las pautas están dadas por lo que acontece, no por liderazgos; el entorno marca las dinámicas y movimientos estratégicos en una masa que se adapta a sus propios requerimientos y entre sí, respetándose y evitando los conflictos a pesar de sus diferencias. El enjambre social nace de cualquier tipo de vínculos, no necesariamente del corporativismo o de la pertenencia a un partido político. Los miembros del enjambre social no necesitan 
acuerdos en todas sus opiniones, ni en la mayoría de sus puntos de vista, sólo requiere coincidencia en algunos aspectos para movilizarse.

En lo referente al cuándo, la ventaja de los medios de comunicación y en particular de los nuevos medios es que actúan en cualquier momento. El cuándo que cuestiona 0'Donnell ya no es ocasional, porque los medios son permanentes: no se requiere el término de un plazo electoral o del inicio de un período de revisión presupuestal o de la estipulación de una fecha oficial para replicar los informes de los funcionarios. En cada ocasión que se requiera informar, comunicar, deliberar, juzgar y consignar, los ciudadanos pueden usar Facebook, subir a Twitter, proyectar en Periscope, entre otros medios disponibles.

Sobre qué han de utilizar cada uno de los medios, según la pregunta de 0'Donnell para alcanzar la accountability societal, la naturaleza de cada uno de los nuevos medios otorga respuesta: mientras los mass media tradicionales poseen una utilidad unidireccionalmente receptiva (y por eso le limitan al escándalo o a avergonzar), los nuevos medios son multidireccionales y cada uno se ha hecho poseedor de una funcionalidad característica pero no limitativa. Así, Twitter es preferido para provocar movilizaciones. Los blogs son espacios deliberativos o de periodismo independiente que completan al periodismo de investigación que tanto apreció 0’Donnell. Facebook se distingue por su calidad de difusión aunada al crecimiento y la nueva web federada promueve la colaboración, protección y organización entre usuarios y los mismos medios.

En lo que concierne a cuáles serían las consecuencias, los nuevos medios ilustran con facilidad, según la agenda de 0'Donnell, los efectos de la accountability societal. Muchos son los casos conocidos ya a nivel mundial que pueden enunciarse: desde La primavera árabe, pasando por el 15M español, el Occupy Wall Street norteamericano, los casos donde ha intervenido Anonymous, WikiLeaks o Edward Snowden, hasta los virales tuits que burlaron la censura del régimen chino cuando el prisionero Liu Xiaobo ganó el Premio Nobel de la Paz en 2010 o las peticiones a favor de Intisar Sharif Abdallah (la mujer condenada a la lapidación en Sudán en 2012), que alcanzaron, con 75715 firmas recopiladas en menos

154 de un mes por Amnistía Internacional, a transformar el expediente judicial para salvarle la vida.

Ahora bien, las potencialidades de los new media para hacer uso de la voz en el sentido en que 0'Donnell sigue a Hirschmann, como hemos apuntado, presenta dos paradojas. La primera consiste en la dialéctica entre activismo y participación ciudadana o cívica. La segunda sobre la real posibilidad de eficiencia política o, inclusive, sobre los efectos contraproducentes de la accountability societal en su dinámica de horizontalización. 
En relación con la primera paradoja, Howard ${ }^{53}$ ha descrito cómo el uso de las plataformas electrónicas inicia como foros de posicionamiento político y devienen en espacios de quejas y exigencias de servicios públicos; o cómo las redes sociales logran altos grados de expresión o cohesión entre oprimidos, pero no alcanzan compromisos sustantivos o influencia real para establecer la agenda pública. Es decir, la participación en los new media corre el riesgo de quedarse o denigrar en activismo de delgado corte cívico o, lo que es peor, como argumenta Morozov, ${ }^{54}$ de auto-sabotearse restando visibilidad y valor al activismo fuera de línea, al activismo real y no virtual.

Respecto a la segunda paradoja, es importante destacar las conclusiones de los teóricos más significativos: Reinhgold ${ }^{55}$ visualizó que las Tic serían una nueva versión de la mercantilización de la esfera pública, además de estar sujetas al control sobre la banda ancha para vigilar y desinformar, ello por no aludir a la colonización y manipulación de los medios de internet que siempre están en riesgo de ser expropiados.

Barber ${ }^{56}$ indagó: “¿Hasta qué punto son democráticas las nuevas tecnologías de telecomunicación?” Concluyó que "Es la política quien hará democrática a la tecnología. La tecnología no hará democrática a la política. La política es lo primero por lo que hay que luchar para conseguir una tecnología democrática”. Después de poco más de media década, y considerando el desarrollo interactivo de la web, Lidén ${ }^{57}$ también cuestionó: "Is e-democracy more than democratic?" para concluir respondiendo: "la democracia electrónica no puede ser por sí misma totalmente democrática si el sistema político en el que está incrustado no es democrático".

Más recientemente entre la polémica de Howard y Morozov, ${ }^{58}$ éste último adoptó una conclusión más moderada dentro de la real politik: "El 'engaño' [...] se refiere no sólo a nuestra tendencia a ver internet como el 'último libera-

\footnotetext{
${ }^{53}$ HowARD, PHILIP, "Social media, civic engagement, and the slacktivism hypothesis: lessons from Mexico's "El Bronco", Journal of International Affairs, vol. 70, núm. 1, pp. 55-73. HowARD, PHILI, "Participation, Civics and your next coffee maker", Policy and Internet, vol. 6, núm. 2, pp. 199-201.

${ }^{54}$ Morozov, Evegny, "From Slacktivism to Activism", Net Effect blog. Disponible en: http://neteffect.foreignpolicy.com/ posts/2009/09/05/from_slacktivism_to_activism

${ }^{55}$ ReINHGOLD, HowARD, The virtual community: homesteading on the electronic frontier, Estados Unidos, Harper Perennial Paperback, 1993.

${ }^{56}$ Barber, Benjamin, "¿Hasta qué punto son democráticas las nuevas tecnologias de telecomunicación?", IDP Revista de Internet, Derecho y Política, núm. 3, p. 26.

${ }^{57}$ LIDÉN, GUSTAV, "Is e-democracy more than democratic? - An examination of the implementation of socially sustainable values in e-democratic processes", EEG, vol. 10, núm. 1, p. 85.

${ }^{58}$ Morozov, Evegny, "Response to Philip N. Howard's review of The Net Delusion: The Dark Side of Internet Freedom", Perspectives on Politics, vol. 9, núm. 4, p. 897.
} 
dor', sino también a nuestra falsa creencia de que es una herramienta que los legisladores occidentales pueden utilizar a voluntad y sin consecuencias”. Es decir, los medios imponen sus propios límites tanto a los gobernantes como a los ciudadanos, pero sobre todo provocan que mutuamente se limiten, con la intención de establecer un nuevo equilibrio político por el cual participan en el proceso de horizontalización del poder y de la accountability societal.

Además, la mera exposición en los medios de la accountability societal, en nuestra opinión, puede provocar un grave equívoco. La accountability puede interpretarse como una práctica exitosa en la medida que informa, da cuenta y se responsabiliza de las decisiones tomadas y las acciones ejecutadas por los gobernantes. Sin embargo, esto no implica su equivalencia con la responsiveness. Si bien es cierto que un campo semántico de la accountability es dar cuenta de las propias acciones y asumir una responsabilidad sobre lo decidido o ejecutado, ello no significa responsiveness en el sentido de obrar responsablemente para la construcción, cuidado, administración y distribución del bien general. Tampoco es equivalente a la reciprocidad que debe guardar el gobierno al actuar conforme a los deseos de los ciudadanos. Es decir, no basta con transparentar las propias acciones; es necesario que los hechos sobre los que versa la accountability tengan correspondencia con la voluntad ciudadana. De poco valdría la transparencia y la responsabilidad de las acciones gubernamentales si éstas fueran tomadas unilateralmente y presentaran grandes diferencias con las demandas o exigencias ciudadanas.

La vigencia de la accountability societal de 0'Donnell, a pesar de sus límites, también se hace efectiva al lograr su horizontalización, más allá de los casos, cuando institucionaliza mecanismos de participación ciudadana. Las estrategias mediáticas activan las demandas de transparencia y rendición de cuentas que surgen desde la verticalidad ascendente hasta la movilización de las instancias horizontales del poder ejecutivo, judicial, legislativo, en las escalas federales, estatales y municipales, amén de la configuración parlamentaria bicameral o de las novedosas figuras de participación ciudadana que permiten instaurar temas y auditorias en la agenda pública. La participación ciudadana, junto con la fiscalización y auditoría de una parte de las finanzas públicas, ha tenido éxitos ejemplares en América Latina, sobre todo en la horizontalización de la accountability societal, ejemplificada en los presupuestos participativos de las municipalidades brasileñas de Porto Alegre, Rio Grande y Belo Horizonte, ${ }^{59}$

\footnotetext{
59 Peixoto, Tiago, "Presupuestos participativos más tecnología. La fórmula perfecta para la inclusión y la participación ciudadana", Perspectiva dossier, vol. 2, pp. 42-45. Disponible en: http://www.revistaperspectiva.com/dossier-contenido/2/presupuesto-participativo-tecnologia-la-formula-perfecta-para-la-inclusiony-la-participacion-ciudadana
} 
donde se evidencia el éxito de su responsiveness en la medida que dichos esquemas de participación no se extinguen.

Finalmente, puede decirse que la accountability societal concebida por 0’Donnell en vinculación e intersección con la accountability horizontal cubre el aspecto de la rendición de cuentas, la transparencia y las garantías de legalidad y legitimidad del nuevo modelo de la democracia líquida. ${ }^{60}$ Este modelo ejemplifica la horizontalización descrita por 0'Donnell en varios casos: en el Partido Pirata de Alemania y Suecia, las plataformas ciudadanas Ahora Madrid y Barcelona en Comú de España y el Movimento 5 Stelle en Italia, por mencionar los casos donde la verticalidad social ascendente, de facto, activa controles de horizontalidad gubernamental. En América Latina, región a la cual 0’Donnell siempre prestó mucha atención, la horizontalización se pretende en el Partido de la Red y el Wikipartido o Wikipolítica, en Argentina y México, respectivamente, y seguramente se cumplirá cuando las redes extiendan su visible democracia interna a la democracia de toda una nación.

\section{Bibliografía}

Aguirre, Jorge, La Democracia Líquida. Los nuevos modelos políticos en la era digital, Barcelona, uoc, 2016.

Arendt, Hannah, Entre el pasado y el futuro, Barcelona, Península, 1996.

Barber, Benjamín, “¿Hasta qué punto son democráticas las nuevas tecnologías de telecomunicación?”, IDP Revista de Internet, Derecho y Politica, núm. 3.

Berg-Schlosser, Dick, "The quality of democracies in Europe as measured by current indicators of democratization and good governance", Journal of Communist Studies and Transition Politics, vol. 20, núm. 1.

Carpintero, Enrique, "El concepto de 'posverdad': una nueva mentira”, Revista Topía. [Consulta: 19 de mayo, 2017]. Disponible en: https://www.topia.com.ar/articulos/concepto-posverdad-una-nueva-mentira

CAstells, Manuel, La Galaxia Internet, España, Plaza y Janés, 2001.

Collingwood, VIVIEN, Good governance and the World Bank, Reino Unido, University of Oxford, 2003.

DAHL, RoBert, La poliarquía. Participación y oposición, Madrid, Tecnos, 1989.

Elgueta, Raúl, "Resención de Peruzzotti, Enrique y Catalina Smulovitz (eds.). 2002. Controlando la política: ciudadanos y medios en las nuevas democracias. Buenos Aires: Editorial Temas, 325 pp.”, Revista de Ciencia Politica, vol. 23, núm. 2.

\footnotetext{
${ }^{60}$ Aguirre, Jorge, La Democracia Líquida. Los nuevos modelos politicos en la era digital, Barcelona, voc, 2016.
} 
Foucault, Michel, Obras esenciales, vol. II, Estrategias de poder, Barcelona, Paidós, 1999.

García Gual, Carlos, “La Grecia antigua”, en Fernando Vallespín (ed.), Historia de la teoría política, I, Madrid, Alianza, 1990.

Habermas, Jurgen, Historia y crítica de la opinión pública, Barcelona, Ediciones G. Gili, 2007.

Held, David, Modelos de democracia, Madrid, Alianza, 1991.

Hirschmann, Albert, Exit, Voice and Loyalty. Responses to Decline in Firms, Organizations, and States, Cambridge, Harvard University Press, 1970.

HowARD, PHILIP, "Social media, civic engagement, and the slactivism hypothesis: lessons from Mexico's ‘El Bronco”, Journal of International Affairs, vol. 70, núm. 1.

HowARD, PHILIP, "Participation, Civics and your next coffee maker", Policy and Internet, vol. 6, núm. 2.

Kaufmann, Daniel, Kraay, Aart, y Mastruzzi, Massimo, "The Worldwide Governance Indicators: Methodology and Analytical Issues”, 2010 [Consulta: 24 de abril, 2017]. Disponible en: http://info.worldbank.org/

LidÉn, Gustav, "Is e-democracy more than democratic? -An examination of the implementation of socially sustainable values in e-democratic processes", EJEG, vol. 10, núm. 1.

Machiavelli, Niccolò, De principatibus, México, Trillas, 1999.

Malena, Carmen, Forster, Reiner, y Singh, Jamejay, "Social accountability. An Introduction to the concept and Emerging Practice", World Bank, Social Development Papers, núm. 76.

Maravall, José María, Accountability and the survival of governments, Madrid, Centro de Estudios Avanzados en Ciencias Sociales, 2005.

Morlino, Leonardo, "What is 'good' democracy?", Democratization, vol. 11, núm. 5. Morozov, Evegny, "Response to Philip N. Howard's review of The Net Delusion: The Dark Side of Internet Freedom”, Perspectives on Politics, vol. 9, núm. 4.

Morozov, Evegny, "From Slacktivism to Activism", Net Effect blog. [Consulta: 28 de noviembre, 2017]. Disponible en: http://neteffect.foreignpolicy.com/ posts/2009/09/05/from_slacktivism_to_activism

Natera, Antonio, "Nuevas estructuras y redes de gobernanza", Revista Mexicana de Sociología, vol. 67, núm. 4.

0’Donnell, Guillermo, "Rendición de cuentas horizontal y nuevas poliarquías", Nueva Sociedad, núm. 152.

O’Donnell, Guileermo, “Accountability horizontal: la institucionalización legal de la desconfianza política”, POSTData, Revista de Reflexión y análisis político, núm. 7.

O’Donnell, Guillermo, Disonancias: críticas democráticas a la democracia. Buenos 
Aires, Prometeo, 2007.

Paniagua, Abraham, José Borunda e Ignacio Camargo, “Transparencia, participación ciudadana y gobierno electrónico: el caso del gobierno local de Ciudad Juárez, México”, Sociedade e Cultura, año 15, núm. 1.

Partido Comunista Obrero EsPaÑol, 2013, Islandia: radiografía de una revolución "ciudadana". [Consulta: 19 de mayo, 2017]. Disponible en: http://www. pcoe.net/actualidad1/actualidad-internacional/444-islandia-radiografia-de-una-revolucion-ciudadana

Pasquino, Gianfranco, Nuevo curso de ciencia política, México, Fondo de Cultura Económica, 2011.

Peixoto, Tiago, "Presupuestos participativos más Tecnología. La fórmula perfecta para la inclusión y la participación ciudadana”, Perspectiva dossier, vol. 2. [Consulta: 12 de enero, 2015]. Disponible en: http://www.revistaperspectiva. com/dossier-contenido/2/presupuesto-participativo-tecnologia-la-formula-perfecta-para-la-inclusiony-la-participacion-ciudadana

Peruzzotti, Enrique y Smulovitz, Catalina, Controlando la politica. Ciudadanos y medios en las nuevas democracias latinoamericanas, Buenos Aires, Editorial Temas, 2002.

Platón, Diálogos, IV. República, Madrid, Gredos, 2008.

REINHGOLD, HOWARD, The virtual community: homesteading on the electronic frontier, Estados Unidos, Harper Perennial Paperback, 1993.

SAlas, JaVier, “La gran cizaña de los ‘bots’ de internet”, El País, año 41, núm. 14749. SÁnchez de Dios, MANuel, "Nueva perspectiva de la responsabilidad política: la "teoría de la agencia’”, Revista de las Cortes Generales, núm. 67.

Shugart, Matthes, Moreno, ERIKa y Crisp, Brian, "The Accountability Deficit in Latin America" Prepared for the conference on "Institutions, Accountability, and Democratic Governance in Latin America”, Kellogg Institute for International Studies, University of Notre Dame, Notre Dame, Indiana, May 8-9, 2000. [Consulta: 7 de agosto, 2017]. Disponible en: https://www3.nd.edu/ kellogg/faculty/research/pdfs/Shugart.pdf

Smulovitz, Catalina y Peruzzotti, EnRique, "Societal Accountability in Latin America”, Journal of Democracy, vol. 11, núm. 4.

Tilly, Charles, y Wood, Lesley, Social movements, 1768-2012, Boulder, Paradigm, 2013.

VAN DiJK, JAN, “Models of Democracy and Concepts of Communication”, K. Hacker and Jan van Dijk (eds.), Digital Democracy. Issues of Theory and Practice, Londres, Thousand Oaks CA, Nueva Delhi, Sage, 2000.

WORLD BANK, "Empowering people by transforming institutions: social development in World Bank operations”, 2005. [Consulta: 4 de mayo, 2017] Disponible en: http://documents.worldbank.org/curated/en/563751468780547056/ 
Empowering-people-by-transforming-institutions-social-development-in-World-Bank-operations

WoRLD BANK, "Social accountability and demand for good governance, 2013”, World

Bank. [Consulta: 5 de mayo, 2017]. Disponible en: http://www.worldbank. org/en/topic/socialdevelopment/brief/social-accountability

ZAFRA, JosÉ, "Responsabilidad política del gobierno: cuestiones fundamentales", en M. Ramírez (ed.), El control parlamentario en las democracias pluralistas, Barcelona, Labor, 1978. 